\title{
The effect of BI 409306 on heart rate in healthy volunteers: a randomised, double-blind, placebo-controlled, crossover study
}

\author{
Fabian Müller ${ }^{1} \mathbb{D}$ - Michael Sand ${ }^{2}$. Glen Wunderlich ${ }^{2}$. Jasmin Link ${ }^{1} \cdot$ Christian Schultheis $^{1}$. \\ Chantaratsamon Dansirikul ${ }^{1} \cdot$ Rucha Sane $^{2} \cdot$ Roman Laszlo $^{3} \cdot$ Jürgen M. Steinacker ${ }^{3}$
}

Received: 17 March 2021 / Accepted: 4 January 2022 / Published online: 28 January 2022

(c) The Author(s) 2022

\begin{abstract}
Purpose The potent, selective phosphodiesterase-9A inhibitor BI 409306 may be beneficial for patients with attenuated psychosis syndrome and could prevent relapse in patients with schizophrenia. Transient BI 409306-dependent increases in heart rate (HR) demonstrated previously necessitated cardiac safety characterisation. We evaluated cardiac effects of BI 409306 in healthy volunteers during rest and exercise.

Methods In this double-blind, three-way crossover study, volunteers received placebo, BI $40930650 \mathrm{mg}$ or $200 \mathrm{mg}$ in randomised order (same treatment on Days 1 [resting] and 3 [exercise]). Cardiopulmonary exercise testing was performed twice post treatment on Day 3 of each period. BI 409306-mediated effects on placebo-corrected change from baseline in resting HR $(\Delta \Delta \mathrm{HR})$ were evaluated based on exposure-response analysis and a random coefficient model. Adverse events (AEs) were recorded.

Results Overall, 19/20 volunteers completed. Resting $\Delta \Delta$ HR versus BI 409306 concentration yielded a slope of 0.0029 beats/min/nmol/L. At the geometric mean (gMean) maximum plasma concentration $\left(C_{\max }\right)$ for BI 40930650 and $200 \mathrm{mg}$, predicted mean $(90 \% \mathrm{CI}) \Delta \Delta \mathrm{HRs}$ were $0.80(-0.76,2.36)$ and $5.46(2.44,8.49)$ beats $/ \mathrm{min}$, respectively. Maximum adjusted mean differences from placebo $(90 \% \mathrm{CI})$ in resting HR for BI 40930650 and $200 \mathrm{mg}$ were $3.85(0.73,6.97)$ and $4.93(1.69$, 8.16) beats/min. Maximum differences from placebo in resting HR occurred at/near gMean $C_{\max }$ and returned to baseline after approximately $4 \mathrm{~h}$. The proportion of volunteers with AEs increased with BI 409306 dose.

Conclusion Observed hemodynamic effects following BI 409306 administration were of low amplitude, transient, and followed the pharmacokinetic profile of BI 409306.
\end{abstract}

Keywords BI $409306 \cdot$ Phosphodiesterase 9 - Cardiovascular safety · Cardiopulmonary exercise testing · Pharmacokinetics

\section{Introduction}

Attenuated psychosis syndrome (APS) and schizophrenia have been associated with abnormalities in glutamatergic neurotransmission related to impaired $N$-methyl-D-aspartic acid (NMDA) receptor signalling [1-3]. Activation of the NMDA receptor leads to postsynaptic signalling events via

Fabian Müller

fabian_1.mueller@boehringer-ingelheim.com

1 Boehringer Ingelheim Pharma GmbH \& Co. KG, Biberach an der Riss, Germany

2 Boehringer Ingelheim Pharmaceuticals, Inc, Ridgefield, CT, USA

3 Division of Sports and Rehabilitation Medicine, Ulm University Hospital, Ulm, Germany increases in second messengers such as cyclic guanosine monophosphate (cGMP) [4]. It has been suggested that during NMDA receptor hypofunction, inhibition of phosphodiesterase 9A (PDE9A), which hydrolyses cGMP, could increase intracellular cGMP concentrations, thus restoring NMDA receptor signalling. This restoration of function would lead to strengthened synaptic plasticity and stabilisation via enhanced long-term potentiation, and could therefore benefit patients with APS and schizophrenia relapse [5-7].

BI 409306, a potent and selective PDE9A inhibitor that may improve NMDA signalling, is currently under clinical development as a potential treatment for APS [8] and for prevention of relapse in schizophrenia [9]. Clinical studies have shown that single and multiple doses of BI 409306 are well tolerated, and no cardiovascular safety signals were observed 
in healthy volunteers $[7,10-13]$ or in patients with schizophrenia [14]. However, there were some concerns about potential cardiovascular effects. In one study, one healthy volunteer in the $350 \mathrm{mg}$ dose group experienced an episode of transient sinus tachycardia, which was of mild intensity and did not exceed 120 beats/min [7]. In another Phase I study, a brief and transient increase in supine heart rate (HR) was observed in volunteers with predicted cytochrome P450 isoform 2C19 (CYP2C19) poor metaboliser status who received a single dose of BI $409306100 \mathrm{mg}$ [15]. Based on retrospective pharmacometric modelling of the available combined Phase I data (unpublished data), an increase in HR of 7-13 beats/min was projected at high plasma exposure (i.e. at the 95th percentile of the observed maximum plasma concentration in 'CYP2C19 poor metabolisers' following a single dose of BI $409306100 \mathrm{mg}$ ).

Considering these previous data regarding the potential cardiac effects of BI 409306, a dedicated safety evaluation with an emphasis on characterising cardiac safety was deemed important. Thus, the current trial was conducted in young, healthy volunteers with the anticipated therapeutic dose and a supra-therapeutic dose of BI 409306. The potential effects of BI 409306 on cardiopulmonary function were also assessed under exercise conditions. Specifically, the effects of BI 409306 on HR, oxygen uptake, and oxygen pulse are explored in this article.

\section{Methods}

\section{Study design}

This was a randomised, placebo-controlled, double-blind, double-dummy, three-way crossover study in healthy male volunteers (Fig. 1; clinicaltrials.gov: NCT02438683). Two doses of BI 409306 were used: $50 \mathrm{mg}$ (anticipated therapeutic dose) and $200 \mathrm{mg}$ (anticipated supra-therapeutic dose). The supra-therapeutic dose was chosen to allow for evaluation of potential cardiac effects at the upper level of the exposure range, thereby providing information that will allow the assessment of an acceptable safety margin. In a first-in-human trial, single doses of BI $409306350 \mathrm{mg}$ showed an acceptable safety and tolerability profile in young, healthy males genotyped as extensive metabolisers of CYP2C19, an enzyme involved in oxidative metabolism of BI 409306 [7]. As no volunteers with poor CYP2C19 metabolism were included in the present study, a lower dose of $200 \mathrm{mg}$ was expected to be well tolerated, and was selected for use in the current trial.

Volunteers were randomised (1:1:1:1:1:1) to one of the 6 treatment sequences, in which they received placebo or BI 409306 (50 $\mathrm{mg}$ or $200 \mathrm{mg}$ ) at rest (Day 1) followed by the same treatment during exercise (Day 3). Each treatment sequence received the three treatments in a different order, as shown in Fig. 1.

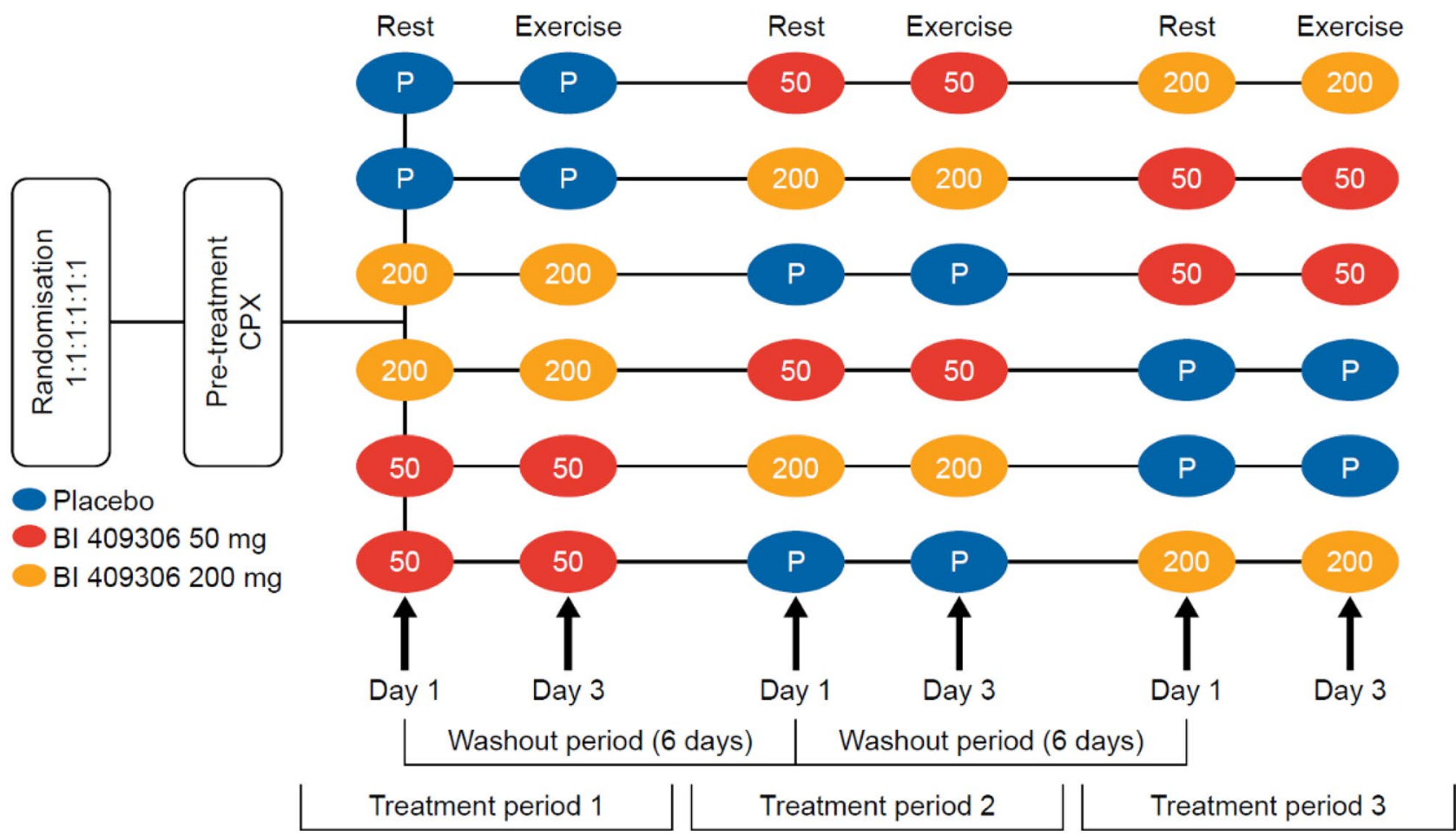

Fig. 1 Study design. CPX cardiopulmonary exercise testing 
Investigators and volunteers were blinded to trial treatments. BI 409306 was administered as 50-mg film-coated tablets, with each dose consisting of either 1 tablet of BI 409306 and 4 tablets of placebo (BI $40930650 \mathrm{mg}$ treatment group), 4 tablets of BI 409306 and 1 tablet of placebo (BI $409306200 \mathrm{mg}$ treatment group), or 5 tablets of placebo (placebo treatment group), to ensure that blinding was maintained.

Volunteers were admitted to the trial site in the morning before the first administration of trial medication in each period (Day 1) and in the evening before the second administration of trial medication (Day 2). Volunteers were then kept under medical surveillance for at least $10 \mathrm{~h}$ following administration of trial medication. During in-house stay, food and water intake was standardised and restricted to those provided by site staff.

For the evaluation of the electrocardiogram (ECG) endpoints, continuous ECGs were collected using 12-lead Holter recorders (CM 3000-12, GETEMED AG, Berlin, Germany) on Days 1 and 3 of each treatment period. On Day 1, triplicate ECGs were extracted under resting conditions. On Day 3, Holter ECGs were used to monitor and evaluate HR under exercise conditions. Immediately after the period for ECG extraction, plasma samples were taken for pharmacokinetic analysis. Holter ECGs were evaluated by a central ECG laboratory (nabios GmbH, Munich, Germany).

On rest (Day 1) and exercise (Day 3) days, plasma samples were collected before administration of the study medication and post administration at $20 \mathrm{~min}, 30 \mathrm{~min}, 45 \mathrm{~min}$, then every $30 \mathrm{~min}$ from 1 to $3 \mathrm{~h}$, and at $4 \mathrm{~h}, 6 \mathrm{~h}$, and $10 \mathrm{~h}$. On Day 1 , one additional sample was collected at $8 \mathrm{~h}$. On Day 3, two additional samples were collected at $2 \mathrm{~h} 20 \mathrm{~min}$ and $2 \mathrm{~h}$ $45 \mathrm{~min}$ after administration - this enabled identical relative blood sampling times during the two cardiopulmonary exercise (CPX) tests (see below) on that day. Samples were withdrawn using an indwelling venous catheter, or by venepuncture. BI 409306 plasma concentrations were measured using a validated liquid chromatography coupled to tandem mass spectrometry (LC-MS/MS) assay with $\left[{ }^{13} \mathrm{C}_{2}, \mathrm{D}_{4}\right] \mathrm{BI} 409603$ as the internal standard. Chromatography was performed on an analytical reverse-phase column with gradient elution. Detection and quantification used electrospray ionisation in the positive ion mode. The lower limit of quantification was $1.50 \mathrm{nmol} / \mathrm{L}$.

Prior to the first treatment period, two sessions (separated by at least 1 day) of CPX were performed (Ergostik, Geratherm Respiratory GmbH, Germany; CardioPart 12, AMEDTEC Medizintechnik GmbH, Germany, and ergometer ergoselect $200 \mathrm{BP}$, ergoline $\mathrm{GmbH}$, Germany). For both sessions, CPX was performed using a ramp protocol: after 3 min of unloaded pedalling, workload was increased from 6 watts $(\mathrm{W})$ by $25 \mathrm{~W} / \mathrm{min}$ until maximal exertion. The purpose of the first CPX session was purely to familiarise the subject with the experimental setup; hence, the obtained data were not analysed further. The second CPX session was performed to obtain the workload (in W) at the individual ventilatory threshold (VT1). This workload, at approximately $50 \%$ of maximal oxygen consumption, allows continuous exercise without excess ventilation and without progressively increasing blood lactate [16, 17]. It is known that a steady-state HR is reached 3-5 min after the onset of submaximal exercise below the anaerobic threshold [18], allowing detection of BI 409306-induced changes in HR and other parameters of interest. This submaximal workload was then used during on-treatment exercise as described below. VT1 was determined manually by trained healthcare professionals based on previously published standard approaches [17].

On rest days (Day 1), volunteers were kept at rest for $4 \mathrm{~h}$ after drug intake. On exercise days (Day 3), volunteers performed two CPX sessions at 20 min after drug intake (close to expected geometric mean [gMean] maximum plasma concentration $\left[C_{\max }\right]$ ), and at $2 \mathrm{~h} 20 \mathrm{~min}$ after drug intake. Each CPX consisted of 3 min of low workload pedalling ('warm-up' at one-third of each subject's individual VT1), 10 min of pedalling with constant, submaximal workload (at each subject's individual VT1), and a 5-min recovery period without pedalling. Oxygen uptake and oxygen pulse, the latter as a surrogate for left ventricular stroke volume, were also analysed as parameters of further interest.

\section{Volunteers}

Volunteers were healthy, non-smoking males aged $18-45$ years with a BMI of $18.5-29.9 \mathrm{~kg} / \mathrm{m}^{2}$, a waist-to-height ratio of $<0.5$, and genetically determined not to be CYP2C19 poor metabolisers. Waist-to-height ratio was chosen in addition to BMI to better account for central obesity and ensure a homogenous trial population [19]. In principle, no concomitant therapy was allowed. In case concomitant therapy was necessary (e.g. for the treatment of adverse events [AEs]), the use of CYP2C19 inhibitors, PDE inhibitors, and CYP2C19 inducers were nevertheless to be avoided throughout the whole course of the trial.

Volunteers with repeated systolic blood pressure $<90 \mathrm{~mm}$ $\mathrm{Hg}$ or $>140 \mathrm{~mm} \mathrm{Hg}$, diastolic blood pressure $<50 \mathrm{~mm} \mathrm{Hg}$ or $>90 \mathrm{~mm} \mathrm{Hg}$, or pulse rate $<45$ beats/min or $>90$ beats/min during screening were excluded, as were those with marked baseline prolongation of QT/QTc interval or any other relevant ECG finding at screening.

\section{Endpoints}

The present report focuses on key endpoints related to HR, oxygen pulse, and oxygen uptake. Primary endpoints were the slope of the placebo-corrected change from baseline in resting HR $(\Delta \Delta \mathrm{HR})$ versus BI 409306 plasma 
concentration, $0-10 \mathrm{~h}$ after intake of trial medication (a positive slope $[\beta>0]$ indicates an increase in resting HR with increasing plasma concentrations), and the maximum difference (vs placebo) in change from baseline resting HR for each dose of BI 409306, 0-4 h after intake of trial medication.

Secondary endpoints included the slope of the placebocorrected maximum HR during exercise versus plasma concentration of BI 409306, and the slope of the placebocorrected difference between maximum HR during exercise and recovery HR ( 1 and 5 min after end of exercise) versus plasma concentration of BI 409306. Further endpoints included the slope of the placebo-corrected oxygen uptake and oxygen pulse (volume of oxygen consumed by the body per heartbeat) during exercise steady state versus plasma concentration of BI 409306.

\section{Pharmacokinetic outcome measures}

Pharmacokinetic parameters of interest included $C_{\max }$, the time from dosing to maximum measured concentration of BI 409306 in plasma after single dose $\left(t_{\max }\right)$, the area under the concentration-time curve (AUC) of BI 409306 in plasma over the time interval from 0 extrapolated to infinity after single dose $\left(\mathrm{AUC}_{0-\infty}\right)$, and the terminal half-life of $\mathrm{BI}$ 409306 in plasma $\left(t_{1 / 2}\right)$.

\section{Further safety and tolerability assessments}

Safety and tolerability were assessed based on AE questioning, physical examination, safety laboratory tests, safety ECGs, vital signs (pulse rate, blood pressure), and suicidality (based on the Columbia Suicide Severity Rating Scale [C-SSRS]). Clinically relevant findings in any of these investigations, or in the Holter ECGs, were reported as AEs. Any suicidal ideation during the trial was also reported as an AE. Suicidal ideation with intention to act or with a specific plan and intent, or any suicidal behaviour during the trial, was reported as an SAE. Hepatic injury was defined as AE of special interest (AESI). The investigator assessed all AEs for causal relationship to trial drug treatment. AEs occurring within the residual effect period of BI 409306 (within $24 \mathrm{~h}$ after drug administration) were classified as on-treatment (i.e. treatment-emergent) AEs. AEs were coded using the Medical Dictionary for Regulatory Activities (MedDRA) version 18.0 and analysed according to the concept of volunteers with treatmentemergent AEs.

\section{Statistical analysis}

All volunteers who received $\geq 1$ dose of study drug were included in the treated set (TS), which was used for safety analyses (with the exception of ECG safety assessments). Those in the TS who provided $\geq 1$ evaluable plasma concentration of BI 409306 (not affected by protocol violations relevant to the statistical evaluation of pharmacokinetic parameters) were included in the pharmacokinetic set (PKS), which was used for the descriptive analysis of pharmacokinetic concentrations and parameters. All volunteers in the TS who had $\geq 1$ baseline, and $\geq 1$ post-baseline assessment in 1 treatment period for $\geq 1 \mathrm{ECG}$ interval endpoint were included in the ECG set (ECGS), which was used for all ECG analyses except those assessing the relationship between BI 409306 plasma concentration and ECG variables. Those in the ECGS who provided $\geq 1$ valid drug plasma concentration and a corresponding ECG variable or oxygen variable in any period were included in the pharmacokinetic ECG set (PKECGS), which was used for exposure-response analyses.

The relationship between plasma concentrations and corresponding response variables was investigated using a random coefficient model including an overall fixed slope effect, together with a two-sided $95 \%$ confidence interval (CI) based on the $t$-distribution, as well as a random intercept and slope effect per subject (exposure response analysis, see also Garnett et al. [20]). Additionally, mean $\Delta \Delta \mathrm{HR}$ and its $90 \% \mathrm{CI}$ at the gMean of $C_{\text {max }}$ for each active treatment (BI $40930650 \mathrm{mg}$ or $200 \mathrm{mg}$ ) were estimated. The maximum mean difference
Table 1 Summary of pharmacokinetic parameters of BI 409306 under resting and exercise conditions

\begin{tabular}{|c|c|c|c|c|}
\hline \multirow[t]{2}{*}{ gMean $(\% \mathrm{gCV})$} & \multicolumn{2}{|l|}{ BI $40930650 \mathrm{mg}$} & \multicolumn{2}{|c|}{ BI $409306200 \mathrm{mg}$} \\
\hline & Rest & Exercise & Rest & Exercise \\
\hline $\mathrm{C}_{\max }, \mathrm{nmol} / \mathrm{L}$ & $433(55.0)$ & $388(52.7)$ & $2040(72.5)$ & $2210(40.7)$ \\
\hline $\mathbf{A U C}_{\mathbf{0}-\infty}, \mathbf{n m o l} \bullet \mathbf{h} / \mathbf{L}$ & $811(59.4)$ & $630(60.4)$ & $3790(69.1)$ & $3420(52.2)$ \\
\hline$t_{1 / 2}, \mathrm{~h}$ & $1.03(18.4)$ & $0.985(18.2)$ & $1.17(15.2)$ & $1.11(9.79)$ \\
\hline$t_{\max }, \mathbf{h}^{\mathrm{a}}$ & $1.5(0.333-2.02)$ & $1.0(0.300-1.50)$ & $1.0(0.333-2.50)$ & $1.0(0.467-1.50)$ \\
\hline
\end{tabular}

$\% g C V$ geometric coefficient of variation, $A U C_{0-\infty}$ the area under the concentration-time curve of $\mathrm{BI}$ 409306 in plasma over the time interval from 0 extrapolated to infinity after single dose, $C_{\max }$ maximum plasma concentration, gMean geometric mean, $t_{1 / 2}$ terminal half-life of BI 409306 in plasma, $t_{\max }$ time from dosing to maximum measured concentration of BI 409306 in plasma after single dose

${ }^{a}$ Median (range) 
between BI 409306 treatment and placebo for the change from baseline in corresponding response variables was assessed using mixed-effect model repeat measurement, including period baseline, subject baseline, treatment, time, period, baseline $\times$ time interaction, treatment $\times$ time interaction, and period $\times$ time interaction as fixed effects.
Fig. 2 Geometric mean drug plasma concentration-time profiles of a BI $40930650 \mathrm{mg}$ or b BI $409306200 \mathrm{mg}$ under resting conditions $(0-10 \mathrm{~h})$ or under exercise conditions (48-58 h; PKECGS). Treatment was administered at $0 \mathrm{~h}$ on Day 1 (Rest) and at $48 \mathrm{~h}$ on Day 3 (Exercise). Relative time $(x$-axis) denotes time after drug administration on the respective treatment day. PKECGS pharmacokinetic electrocardiogram set
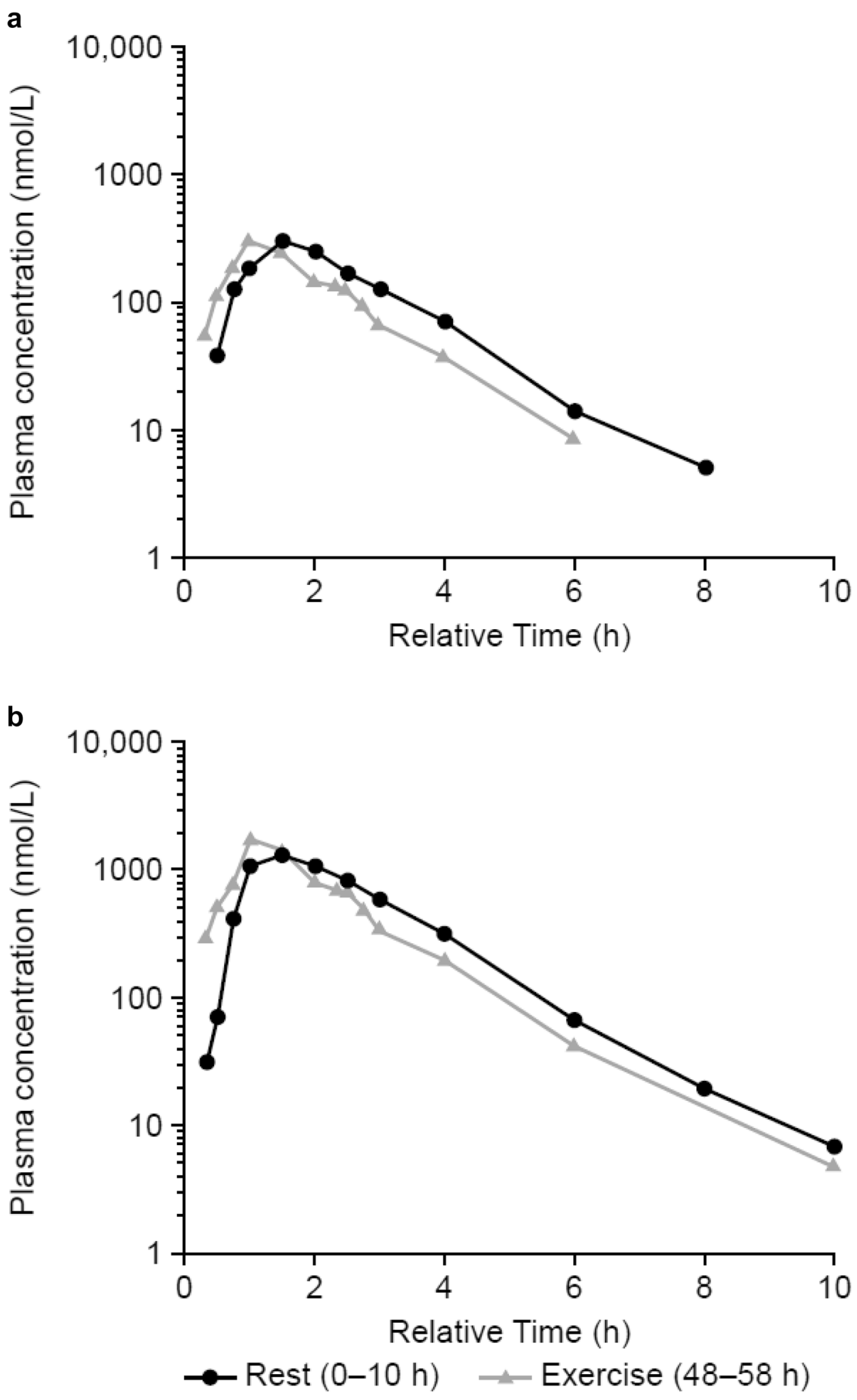


\section{Results}

\section{Study population}

Overall, 20 volunteers entered and 19 completed the study. One subject in treatment sequence placebo/BI 409306 $50 \mathrm{mg} / \mathrm{BI} 409306200 \mathrm{mg}$ discontinued trial participation due to AEs after the first dose of the second treatment period. All 20 volunteers were included in the TS and PKS, while 19/20 volunteers were included in the ECGS and the PKECGS. There were no relevant demographic imbalances between the volunteers entered in the different treatment sequences. Overall, the mean (SD) age and BMI of volunteers were $32.1(8.4)$ years and $24.84(2.56) \mathrm{kg} /$ $\mathrm{m} 2$, respectively. Nineteen volunteers $(95.0 \%)$ were Caucasian, and 1 subject (5.0\%) was black/African American.

\section{Pharmacokinetics}

Pharmacokinetic parameters of BI 409306 (50 and $200 \mathrm{mg}$ ) under resting and exercise conditions are shown in Table 1. The exposures under both conditions were generally similar (Fig. 2). A very brief, transient plateau in BI 409306 plasma concentrations in the elimination phase was observed during the second CPX at both doses in individual volunteers (approximately $2 \mathrm{~h} 20 \mathrm{~min}$ post dose). This may not have been as evident during the first CPX as BI 409306 plasma concentrations were still increasing at that timepoint.

\section{Exposure-response analysis of resting $\Delta \Delta H R$}

Maximum changes in resting HR occurred at/near the time of $C_{\max }$, approximately $1 \mathrm{~h}$ after administration of the study medication, and returned to baseline relatively rapidly, after approximately $4 \mathrm{~h}$ (Fig. 3A). Thus, no delayed effect of BI 409306 on HR was observed. The evaluation of the plasma concentration effect on ECG via the exposure-response model (linear relationship of $\Delta \Delta \mathrm{HR}$ vs BI 409306 plasma concentration) yielded a slope of 0.0029 beats $/ \mathrm{min} / \mathrm{nmol} / \mathrm{L}$ (95\% CI: 0.0012, 0.0046). At the $\mathrm{gMean}_{\mathrm{max}}$ for BI 409306 $50 \mathrm{mg}$, the predicted mean $\Delta \Delta \mathrm{HR}$ was 0.80 beats $/ \mathrm{min}(90 \%$ CI: - 0.76, 2.36); at the gMean $\mathrm{C}_{\max }$ for the 200-mg dose, the predicted mean $\Delta \Delta \mathrm{HR}$ was 5.46 beats $/ \mathrm{min}$ (90\% CI: 2.44 , 8.49) (Fig. 3B).

\section{Repeated measures analysis of resting HR}

The dose effect evaluation on ECG yielded a maximum adjusted mean change in resting HR of 3.85 beats/min (90\% CI: 0.73 ,
Fig. 3 a Time profile of mean BI 409306 plasma concentrations and mean resting $\Delta \Delta \mathrm{HR}$ and $\mathbf{b}$ relationship between BI 409306 plasma concentration and resting $\Delta \Delta \mathrm{HR}$ (PKECGS). Panel a Solid lines represent placebo-corrected change in HR from baseline; dashed lines represent plasma concentration. Panel b Predicted values and 90\% CI are represented by solid lines; gMean $C_{\max }$ at each dose level is represented by vertical lines. $C_{\max }$ maximum plasma concentration, gMean geometric mean, $\Delta \Delta \mathrm{HR}$, placebo-corrected change from baseline in resting heart rate, PKECGS pharmacokinetic electrocardiogram set

6.97) and 4.93 beats/min (90\% CI: 1.69, 8.16) for BI 409306 50 and $200 \mathrm{mg}$, respectively, which occurred at/near the time of $C_{\max }$ for each dose.

\section{Exposure-response analysis of placebo-corrected maximum HR during exercise and recovery}

Assessment of placebo-corrected maximum HR during exercise versus BI 409306 plasma concentration yielded a slope of 0.0054 beats $/ \mathrm{min} / \mathrm{nmol} / \mathrm{L}$ (95\% CI: $0.0032,0.0076)$. At the gMean $\mathrm{C}_{\max }$ for BI $40930650 \mathrm{mg}$, the predicted mean increase in placebo-corrected maximum HR was 2.97 beats/ $\min (90 \%$ CI: $0.80,5.14)$. Predicted mean placebo-corrected maximum HR was not extrapolated to gMean $C_{\max }$ for the $200 \mathrm{mg}$ dose during exercise because all volunteers completed exercise before $C_{\max }$ was reached; therefore, maximum HR during exercise did not coincide with $C_{\max }$. The effect of BI 409306 on placebo-corrected maximum HR at the maximum individual plasma concentration during exercise $(1960 \mathrm{nmol} / \mathrm{L})$ is therefore shown, as opposed to the effect at $C_{\max }$. During exercise, the predicted mean placebo-corrected maximum increase in HR was 11.51 beats/min (90\% CI: 8.14, 14.88; post hoc analysis; Fig. 4).

The HR decrease after the end of exercise was more pronounced at higher BI 409306 plasma concentrations; at the gMean $C_{\max }$ for BI $40930650 \mathrm{mg}$ and $200 \mathrm{mg}$, the predicted placebo-corrected difference between maximum HR during exercise and after $5 \mathrm{~min}$ recovery was 0.58 beats $/ \mathrm{min}(90 \%$ CI: $-1.07,2.23)$ and -4.79 beats/min (90\% CI: $-8.21,-1.37$ ), respectively. Overall, during recovery (1-5 min after cessation of exercise), HR decreased and there was no delay in recovery as a result of BI 409306 exposure.

\section{Exposure-response analysis of placebo-corrected oxygen uptake and oxygen pulse during exercise}

Assessment of the relationship between placebo-corrected oxygen uptake during exercise versus plasma concentration of BI 409306 provided a slope of $0.0004 \mathrm{~mL} / \mathrm{kg} / \mathrm{min} /(\mathrm{nmol} / \mathrm{L})$ (95\% CI: $-0.0001,0.0009)$. At the gMean $C_{\max }$ for BI 409306 $50 \mathrm{mg}$, the predicted placebo-corrected oxygen uptake during exercise was $-0.23 \mathrm{~mL} / \mathrm{kg} / \mathrm{min}(90 \% \mathrm{CI}:-0.49,0.04)$. It 

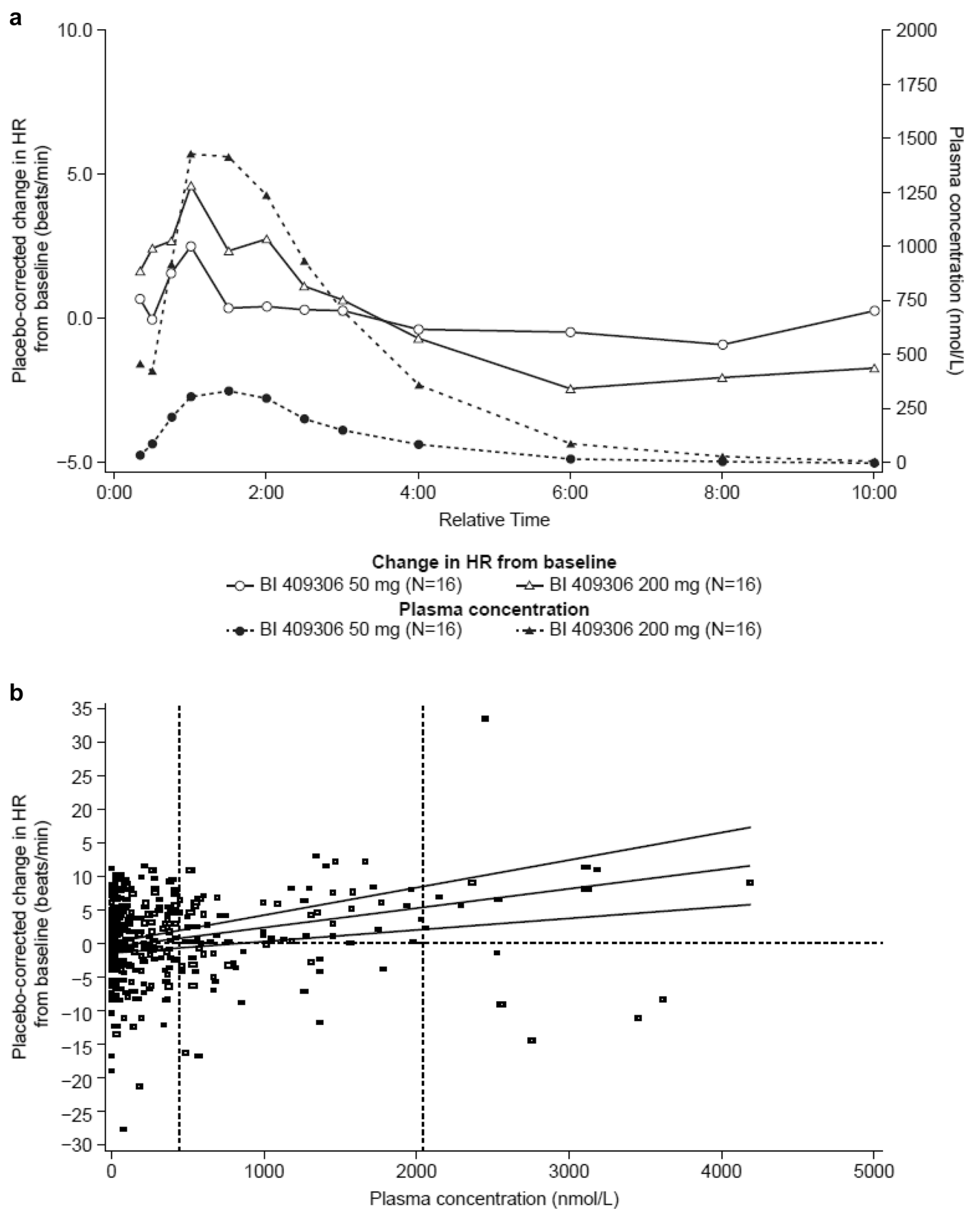

appeared that BI 409306 at the plasma concentrations achieved in the trial did not have a clinically relevant impact on oxygen uptake (Fig. 5A).
Assessment of the relationship between placebo-corrected oxygen pulse during exercise versus plasma concentration of BI 409306 provided a slope of $-0.0007 \mathrm{~mL} / \mathrm{beat} /$ 


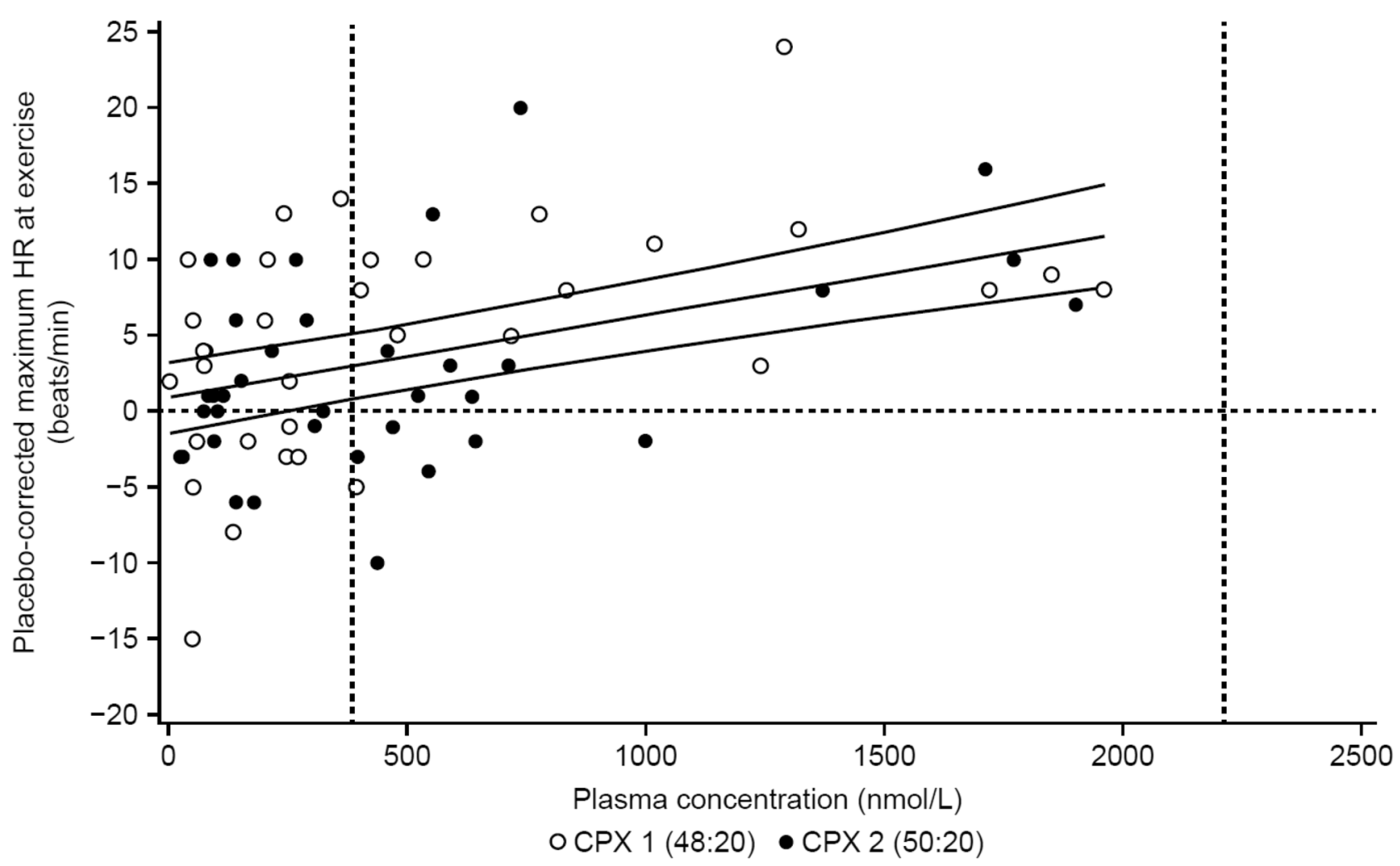

Fig. 4 Relationship between placebo-corrected maximum HR under exercise conditions and BI 409306 plasma concentration (PKECGS). Predicted values and $90 \% \mathrm{CI}$ are shown by solid lines; gMean $C_{\max }$ at each dose level is shown by vertical lines. $C_{\max }$ gMean maximum

(nmol/L) (95\% CI: - 0.0012, - 0.0002). At the gMean $C_{\max }$, the predicted placebo-corrected oxygen pulse during exercise was $-0.30 \mathrm{~mL} / \mathrm{beat}(90 \% \mathrm{CI}:-0.69,0.10)$ for BI 409306 $50 \mathrm{mg}$, demonstrating a minor BI 409306 dose-dependent decrease in oxygen pulse (Fig. 5B).

\section{Adverse events}

Treatment-emergent AEs were reported for 13/20 (65.0\%) volunteers (Table 2). The most frequently reported AEs by system organ class were eye disorders $(9 / 20[45.0 \%]$ volunteers) and nervous system disorders (7/20 [35.0\%] volunteers); none of the AEs in these categories were reported in volunteers receiving BI $40930650 \mathrm{mg}$. AEs increased with dose but with generally similar rates at rest and during exercise. One subject discontinued treatment after experiencing mild ventricular extrasystoles, mild palpitations, and mildly increased HR following BI $40930650 \mathrm{mg}$. All three AEs resolved without therapeutic intervention after $1 \mathrm{~h}$. There were no clinically relevant, treatment-emergent findings in safety-related laboratory assessments, and the C-SSRS plasma concentration, CPX cardiopulmonary exercise testing, HR heart rate, gMean geometric mean, PKECGS pharmacokinetic electrocardiogram set

assessment revealed no suicidal ideation or behaviour. No AEs of severe intensity, AESIs, or SAEs were reported.

\section{Discussion}

BI 409306 concentration-dependent HR increases were observed under both resting and exercise conditions, with the maximum increase occurring at or near the time of $C_{\max }$. These increases in resting HR were transient, with a predicted mean of 5.46 beats $/ \mathrm{min}$ at the expected supratherapeutic dose. Furthermore, exercise testing did not suggest a clinically relevant impact on cardiac function. During recovery, HR decreased appropriately without delayed recovery. These findings are consistent with the brief, transient increase in HR observed in a previous study after a single dose of BI $409306100 \mathrm{mg}$ in CYP2C19 poor metabolisers [15]. The magnitude of the increase in HR was dependent on the plasma concentration of BI 409306; plasma concentrations in the present study were consistent with those reported previously [7]. 

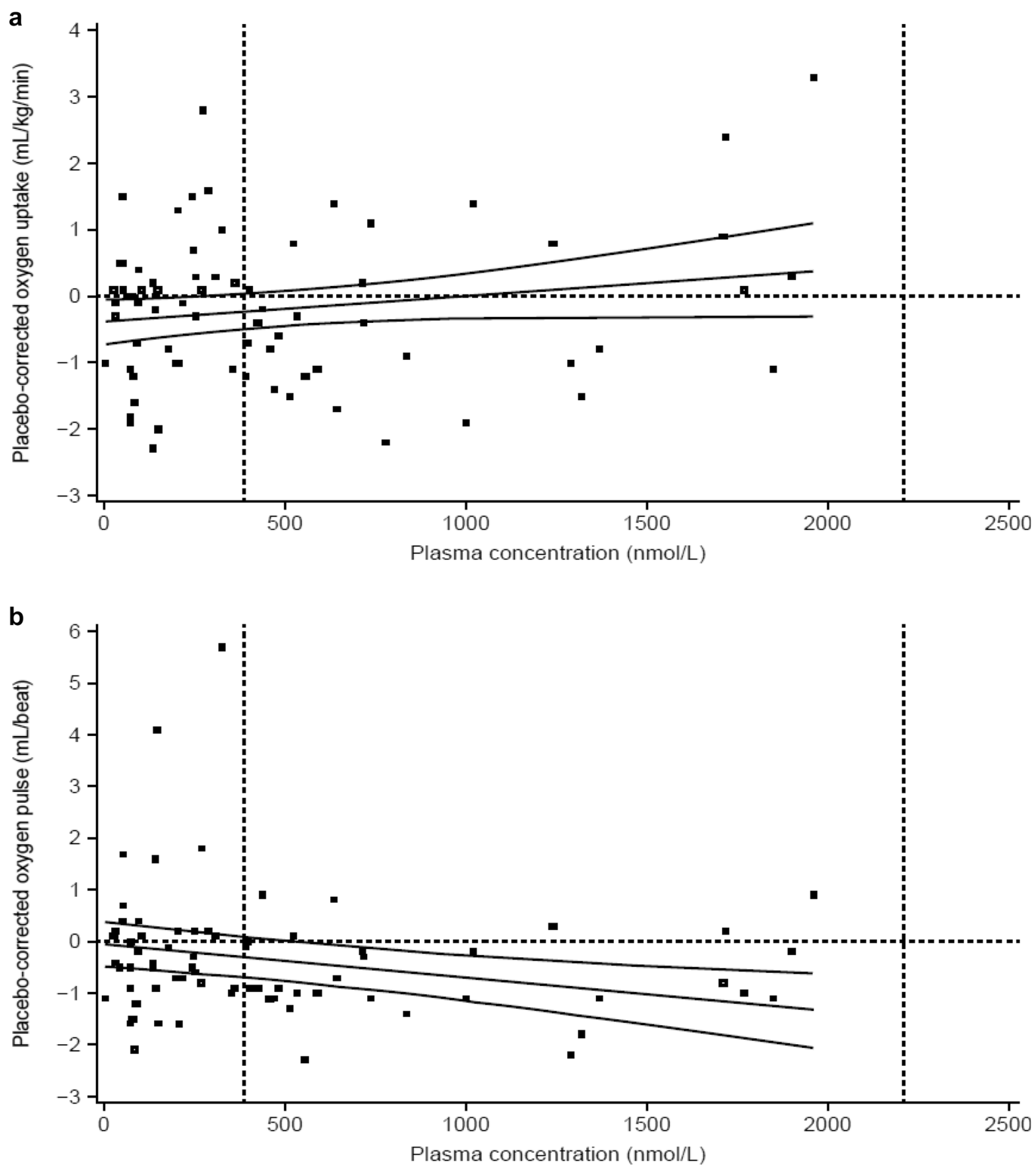

Fig. 5 Relationship between plasma concentrations of BI 409306 and a placebo-corrected oxygen uptake and b placebo-corrected oxygen pulse under exercise conditions (PKECGS). Predicted values and 90\% CI are shown by solid lines; gMean $C_{\max }$ at each dose level is

CPX was chosen to evaluate a potential BI 409306-induced effect on HR under exercise conditions, as this method allows the determination of individual volunteers' VT1 [18]. At shown by vertical lines. $C_{\max }$ gMean maximum plasma concentration, gMean geometric mean, PKECGS pharmacokinetic electrocardiogram set

fixed VT1-defined workloads below the anaerobic threshold, steady-state conditions are normally reached approximately 3-5 min after the onset of exercise and HR is subsequently 
Table 2 Summary of volunteers with treatment-emergent adverse events by treatment, primary system organ class, and preferred term (TS)

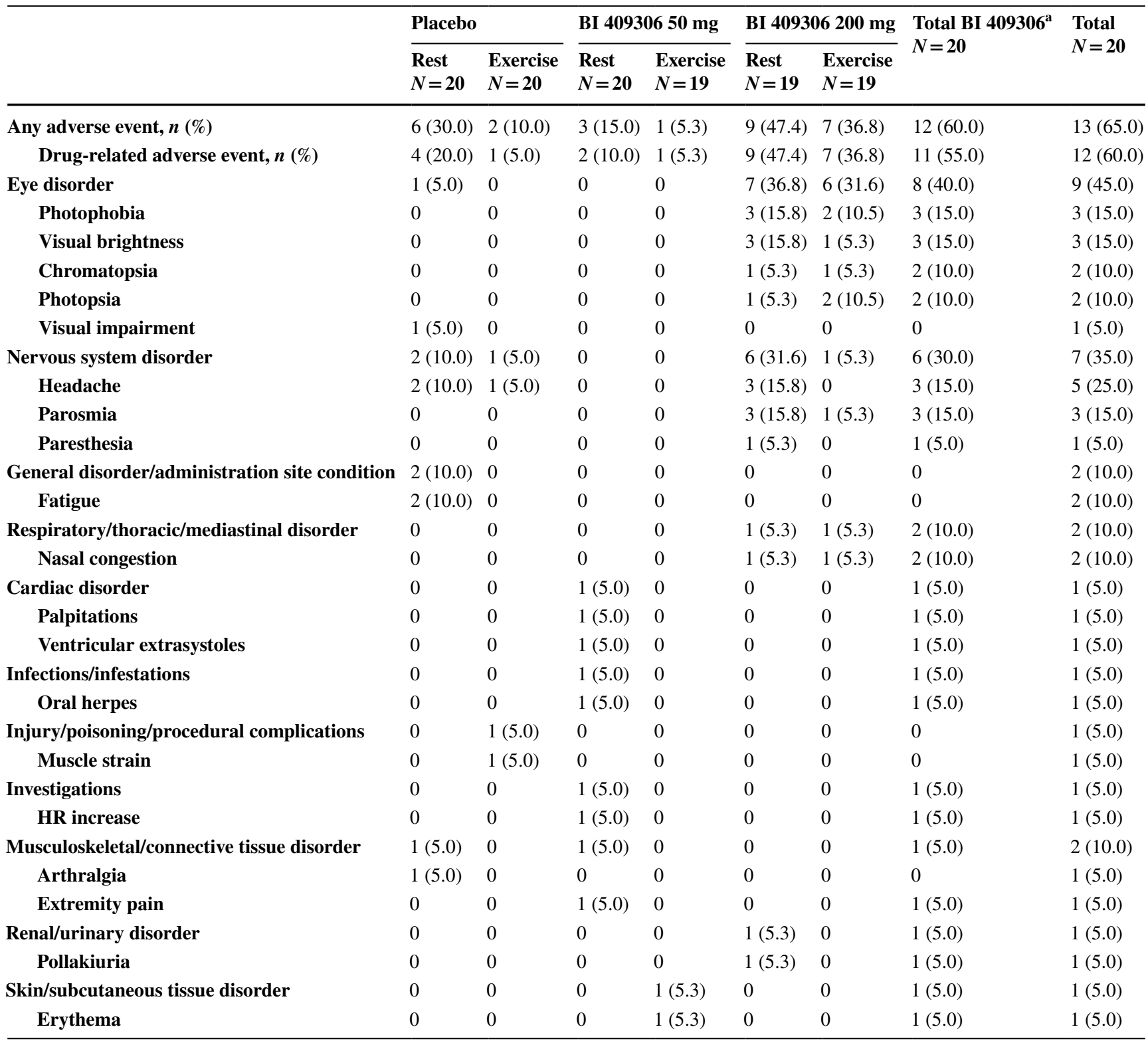

${ }^{a}$ Volunteers with AEs during treatment with BI $40930650 \mathrm{mg}$ and/or during treatment with BI $409306200 \mathrm{mg}$

maintained at reasonably constant levels. Using this VT1defined workload allowed for the meaningful analysis of HR and other parameters of interest as they relate to BI 409306 administration.

Under steady state activity (such as in the current trial), oxygen uptake can be considered to be an indicator of oxygen consumption as a result of metabolic activity [17]. At the plasma concentrations achieved in this trial, BI 409306 did not have a relevant impact on oxygen uptake. As expected, due to BI 409306 concentration-dependent increases in HR, oxygen pulse as a CPX indicator of left ventricular stroke volume [17] showed a minor BI 409306 concentration-dependent decrease. Taken together, the hemodynamic effects of BI 409306 at therapeutic and supratherapeutic doses reported in this study were of low amplitude, transient, and followed the pharmacokinetic profile of BI 409306.

BI 409306 was well tolerated. Of note, the frequency of AEs was higher for the supratherapeutic $200 \mathrm{mg}$ dose than for BI $40930650 \mathrm{mg}$. The most common AEs for BI $409306200 \mathrm{mg}$, which were those related to vision, may have occurred due to direct, transient retinal effects of BI 409306. This is supported by in vitro data linking PDE9A to processes within the cone pathway in the retina [21], and 
it is in line with results from previous trials of BI 409306 [7, 15], particularly one study in which vision-related AEs were only observed at a dose of $200 \mathrm{mg}$ [10].

The mild palpitations, ventricular extrasystoles, and mild HR increase reported for a single subject during treatment with BI $40930650 \mathrm{mg}$ are events that can be observed in healthy volunteers [22, 23], and therefore, may not be directly linked to treatment. However, due to the timing of the onset of these symptoms (increased frequency of ventricular extrasystoles occurred shortly after BI $40930650 \mathrm{mg}$ intake), a causal relationship to the trial drug cannot be ruled out entirely. Nevertheless, these AEs were not considered clinically relevant overall.

One of the limitations of this study is the use of young and exclusively male, healthy volunteers. This population was selected because of the precision required for analysis of the ECG data, as sex- and age-related variability in ECG parameters could have precluded collection of interpretable data. In addition, the sample size was moderate, in line with the exploratory nature of the study. Strengths of this study are the highly controlled setting in a phase I unit, the robust crossover design, and the use of supratherapeutic and therapeutic doses of BI 409306 as well as placebo in a doubleblind fashion. A further strength of this study is the novel evaluation of possible cardiac effects specifically under exercise conditions, which would not routinely be covered in a standard thorough QT trial monitoring potential cardiac effects of a candidate drug.

In conclusion, BI 409306 was well tolerated in young, healthy male volunteers. Transient BI 409306 concentrationdependent increases in HR of low amplitude were observed under resting and exercise conditions. These effects followed the pharmacokinetic profile of BI 409306, and analysis of HR recovery indicated no delay as a result of BI 409306. There was no effect of BI 409306 on oxygen uptake, and oxygen pulse showed a minor BI 409306 concentration-dependent decrease.

Acknowledgements We thank Claudia Völk for her role in the design and conduct of the study, and for her contributions to the development of the manuscript. We thank the team of the Human Pharmacology Centre, Boehringer Ingelheim's Phase I unit, and the team of the Division of Sports Medicine, Ulm University, for the excellent clinical conduct of the study. We acknowledge the editorial support (in the form of initial preparation of the outline based on input from all authors, collation, and incorporation of author feedback to develop subsequent drafts, assembling tables and figures, copyediting, and referencing) provided by Heather Shawcross, PhD, and Mark Condon, DPhil, of Fishawack Communications Ltd., which was funded by Boehringer Ingelheim.

Author contribution All authors were involved in the preparation and review of the manuscript and approved the final version to be submitted. FM and CS contributed to the collection and analysis of study data. CD contributed to the conception and design of the study. GW, MS, and RS contributed to the conception and design of the study and analysis of study data. RL provided new methods or models, and contributed to the conception and design of the study and collection of the study data. JL and JMS provided new methods or models, and contributed to the conception and design of the study and analysis of the study data.

Funding This study was funded by Boehringer Ingelheim and conducted at the Human Pharmacology Centre of Boehringer Ingelheim, Biberach, Germany.

\section{Declarations}

Ethical approval for research involving human participants All procedures were performed in accordance with the ethical standards of the respective independent ethics committee (Ethik-Kommission der Landesärztekammer Baden-Württemberg, Germany) and the competent authority (Bundesinstitut für Arzneimittel und Medizinprodukte, Germany). The study was conducted in accordance with the International Conference for Harmonisation of Technical Requirements for Pharmaceuticals for Human Use Guideline for Good Clinical Practice and local legislation, in accordance with the principles of the Declaration of Helsinki [24, 25].

Role of the sponsor The work presented here, including the conduct of the trial, data analysis and interpretation, was funded by Boehringer Ingelheim. The sponsor was given the opportunity to review the manuscript for medical and scientific accuracy as well as intellectual property considerations.

Informed consent Written informed consent was obtained from all individual participants included in the study.

Conflict of interest The authors met the criteria for authorship as recommended by the International Committee of Medical Journal Editors. FM, CD, JL, CS, GW, and MS are employees of Boehringer Ingelheim. RS is a former employee of Boehringer Ingelheim. RL and JMS received funding from Boehringer Ingelheim for conducting this study.

Open Access This article is licensed under a Creative Commons Attribution 4.0 International License, which permits use, sharing, adaptation, distribution and reproduction in any medium or format, as long as you give appropriate credit to the original author(s) and the source, provide a link to the Creative Commons licence, and indicate if changes were made. The images or other third party material in this article are included in the article's Creative Commons licence, unless indicated otherwise in a credit line to the material. If material is not included in the article's Creative Commons licence and your intended use is not permitted by statutory regulation or exceeds the permitted use, you will need to obtain permission directly from the copyright holder. To view a copy of this licence, visit http://creativecommons.org/licenses/by/4.0/.

\section{References}

1. Dauvermann MR, Lee G, Dawson N (2017) Glutamatergic regulation of cognition and functional brain connectivity: insights from pharmacological, genetic and translational schizophrenia research. Br J Pharmacol 174(19):3136-3160. https://doi.org/ 10.1111/bph.13919

2. Stephan KE, Friston KJ, Frith CD (2009) Dysconnection in schizophrenia: from abnormal synaptic plasticity to failures of self-monitoring. Schizophr Bull 35(3):509-527. https://doi.org/ $10.1093 / \mathrm{schbul} / \mathrm{sbn} 176$

3. Lewis DA, Moghaddam B (2006) Cognitive dysfunction in schizophrenia: convergence of gamma-aminobutyric acid and 
glutamate alterations. Arch Neurol 63(10):1372-1376. https:// doi.org/10.1001/archneur.63.10.1372

4. Bales KR, Plath N, Svenstrup N, Menniti FS (2010) Phosphodiesterase inhibition to target the synaptic dysfunction in Alzheimer's disease. In: Dominguez C (ed) Neurodegener Dised. Springer, Berlin Heidelberg, pp 57-90

5. Cooke SF, Bliss TVP (2006) Plasticity in the human central nervous system. Brain 129(7):1659-1673. https://doi.org/10. 1093/brain/awl082

6. Rezvani AH (2006) Animal models of cognitive impairment. In: Levin E, Buccafusco J (Eds.) ed. CRC Press/Taylor \& Francis.

7. Moschetti V, Boland K, Feifel U, Hoch A, Zimdahl-Gelling H, Sand M (2016) First-in-human study assessing safety, tolerability and pharmacokinetics of BI 409306, a selective phosphodiesterase 9A inhibitor, in healthy males. Brit J Clin Pharmacol 82(5):1315-1324. https://doi.org/10.1111/bcp.13060

8. Keefe R, Woods S, Cannon T, Ruhrmann S, Mathalon D, McGuire P, Fillon G, Rosenbrock H, Sand M (2017) Early intervention in attenuated psychosis syndrome: a phase II study evaluating efficacy, safety, and tolerability of oral BI 409306. Schizophr Bull 43:S216-217

9. Sand M, Brown D, Walling D, Daniels K, McGinniss J (2018) Prevention of Relapse in Schizophrenia: A Phase II Study Evaluating Efficacy, Safety, and Tolerability of Oral BI 409306. Biol Psychiat 83:S421

10. Boland K, Moschetti V, Dansirikul C, Pichereau S, Gheyle L, Runge F, Zimdahl-Gelling H, Sand M (2017) A phase I, randomized, proof-of-clinical-mechanism study assessing the pharmacokinetics and pharmacodynamics of the oral PDE9A inhibitor BI 409306 in healthy male volunteers. Hum Psychopharmacol 32 (1). https://doi.org/10.1002/hup.2569

11. Kim JM, Yum S-YA, Goetz S, Tsuda Y, Sand M, Moschetti V, Jang I-J (2015) Safety, tolerability, and pharmacokinetics of BI 409306: a randomized, placebo-controlled, double-blinded phase I study in Chinese and Japanese healthy male volunteers. Alzheimers Dement 11(Suppl):468

12. Moschetti V, Boland K, Hoch A, Timmer W, Zimdahl-Gelling H, Borta A, Sand M (2015) Safety, tolerability, pharmacokinetics, and pharmacodynamics of multiple rising doses of BI 409306 film-coated tablets given orally once- or twice-daily for 14 days in young and elderly healthy volunteers. Alzheimers Dement 11(Suppl):468-469

13. Wunderlich G, Timmer W, Andersen G, Hoch A, Moschetti V, Boland K, Zimdahl-Gelling H, Borta A, Sand M (2015) Phase I studies evaluating the safety, tolerability, and pharmacokinetics of multiple-rising doses of BI 409306 in young and elderly healthy volunteers. J Prevent Alzheimer's Dis 2(4):324

14. Brown D, Daniels K, Zhang S, Pichereau S, Sand M (2015) Safety, tolerability, pharmacokinetics and pharmacodynamics of BI 409306 film-coated tablets given orally QD for 14 days in patients with schizophrenia. Schizophr Bull 41(Suppl):S304

15. Moschetti V, Kim M, Sand M, Wunderlich G, Andersen G, Feifel U, Jang I-J, Timmer W, Rosenbrock H, Boland K (2018)
The safety, tolerability and pharmacokinetics of BI 409306, a novel and potent PDE9 inhibitor: Overview of three Phase I randomised trials in healthy volunteers. Euro Neuropsychopharmacol 28(5):643-655. https://doi.org/10.1016/j.euroneuro.2018.01.003

16. Roeker K (2013) Die sportmedizinische Laktatdiagnostik: Technische Rahmenbedingungen und Einsatzbereiche. Dtsch Z Sportmed 64(12):367-371

17. Balady GJ, Arena R, Sietsema K, Myers J, Coke L, Fletcher GF, Forman D, Franklin B, Guazzi M, Gulati M, Keteyian SJ, Lavie CJ, Macko R, Mancini D, Milani RV (2010) Clinician's guide to cardiopulmonary exercise testing in adults. Circulation 122(2):191

18. Fletcher GF, Ades PA, Kligfield P, Arena R, Balady GJ, Bittner VA, Coke LA, Fleg JL, Forman DE, Gerber TC, Gulati M, Madan K, Rhodes J, Thompson PD, Williams MA (2013) Exercise standards for testing and training: a scientific statement from the American Heart Association. Circulation 128(8):873-934. https://doi. org/10.1161/CIR.0b013e31829b5b44

19. Ashwell M, Hsieh SD (2005) Six reasons why the waist-toheight ratio is a rapid and effective global indicator for health risks of obesity and how its use could simplify the international public health message on obesity. Int J Food Sci and Nutrition 56(5):303-307. https://doi.org/10.1080/09637480500195066

20. Garnett CE, Beasley N, Bhattaram VA, Jadhav PR, Madabushi R, Stockbridge N, Tornoe CW, Wang Y, Zhu H, Gobburu JV (2008) Concentration-QT relationships play a key role in the evaluation of proarrhythmic risk during regulatory review. J Clin Pharmacol 48(1):13-18. https://doi.org/10.1177/0091270007307881

21. Dhingra A, Tummala SR, Lyubarsky A, Vardi N (2014) PDE9A is expressed in the inner retina and contributes to the normal shape of the photopic ERG waveform. Front Mol Neurosci 7:60. https:// doi.org/10.3389/fnmol.2014.00060

22. Min SS, Turner JR, Nada A, DiMino TL, Hynie I, Kleiman R, Kowey P, Krucoff MW, Mason JW, Phipps A, Newton-Cheh C, Pordy R, Strnadova C, Targum S, Uhl K, Finkle J (2010) Evaluation of ventricular arrhythmias in early clinical pharmacology trials and potential consequences for later development. Am Heart J 159(5):716-729. https://doi.org/10.1016/j.ahj.2010.02.004

23. Hingorani P, Karnad DR, Rohekar P, Kerkar V, Lokhandwala YY, Kothari S (2016) Arrhythmias seen in baseline 24-hour Holter ECG recordings in healthy normal volunteers during phase 1 clinical trials. J Clin Pharmacol 56(7):885-893. https://doi.org/ $10.1002 /$ jcph.679

24. International Conference on Harmonisation of Technical Requirements for Registration of Pharmaceuticals for Human Use Ihtg (1996) Guideline for Good Clinical Practice E6 (1).

25. World Medical Association (2013) WMA Declaration of Helsinki - ethical principles for medical research involving human subjects. J Am Med Assoc 310(20):2191-2194. https://doi.org/10.1001/ jama.2013.281053

Publisher's Note Springer Nature remains neutral with regard to jurisdictional claims in published maps and institutional affiliations. 